\title{
Aortic Arch Aneurysm Repair under Deep Hypothermic Circulatory Arrest
}

\author{
Pokharel JN*, Upreti MR*, Shakya DR*, Koirala B*, sharma J*, Pradhan $S^{\star}$, Timila R ${ }^{\star}$, Rajbansi B ${ }^{\star}$, Chaudhary \\ $\mathrm{SN}^{\star}$, Batta $\mathrm{M}^{*}$, Khan $\mathrm{U}^{\star}$ \\ *Shahid Gangalal National Heart Centre, Bansbari \\ Corresponding: Dr. Jeju N. Pokhrel \\ Shahid Gangalal National Heart Centre, Bansbari, Kathmandu, Nepal Phone Number: 00799-1-43471374 Fax: 00977-1-4371123 \\ Email: jeju25@hotmail.com
}

\begin{abstract}
A 46 years female underwent aortic arch repair surgery under deep hypothermic circulatory arrest (DHCA) and right antegrade cerebral perfusion. The patient was extubnated after 13 hours of the surgery and discharged from SICU on third post operative day and discharged from hospital on sixth postoperative day uneventfully and with excellent neurological functions. It was the first case of aortic arch repair in our hospital. Combination of DHCA and right antegrade cerebral perfusion may be the reason for better neurological outcome.
\end{abstract}

Keywords : Aortic Arch Aneurysm, Deep Hypothermic Circulatory arrest

\section{CASE REPORT}

A 46 years female from Godavari, Lalitpur district was referred to SGNHC from Patan Hospital with the suspicion of a mediastinal mass.

When she was presented in the OPD she had upper rretrosternal chest pain radiating to the back, more in the interscapular region, pricking in nature for the last 8 years, cough for two months, palpitation, $h=$ headache, decreased appetite and marked weight loss.

Her past medical history revealed that she had severe lower chest pain 10 years back and was seen at different hospitals. She was advised for the operation after CT scan of the chest TUTH. The size of the aneurysm of the aortic arch was $7.3 \mathrm{~cm}$ in diamerter. She had gioitre for the last 26 years and 10 years back FNAC was done which showed colloid goitre. She had the features of hypothyroidism and treated with thyroxin for the two years. Similarly she also had hoarseness of the voice since the last 10 years and on examination revealed left vocal cord palsy. She had an epidose of syncope 8 years back.

She smoked since childhood and gave up last two years back. She does not consume alcohol. She is married and has a daughter of 25 years and a son of 23 years. She is a farmer by occupation. She is on atenolol $25 \mathrm{mg}$ once daily for the last 10 years.

\section{General Physical examination:}

Thin built lady having weight of $42 \mathrm{~kg}$ and $155 \mathrm{~cm}$ height having some facial congestion and there was some degree of neck vein distension. Icterus, pallor, cyanosis, oedema, dehydration or clubbing not present. There was multioculated nodular swelling in the right side of the neck. Pulse was 92 per minute and regular, weaker in the left radial and lower extremeties. Blood pressure was $108 / 80 \mathrm{mmHg}$ in the right arm and $88 / 60 \mathrm{mmHg}$ in the left arm both in the sitting position. There was a globular multiobulated mass palpable in the right side of the neck.

\section{Systemic examination:}

No visible pulsation was observed over the chest. Systolic thrill and ejection systolic murmur was present at the aortic areal. Diminished air entry in the left lung field and occasional ronchi was heard Other systemic examination revealed no abnormality. Uupper airwasy was normal with Malampatti Classification grading-I. The Lab investigation were with in normal limits and patient was euthyroid.

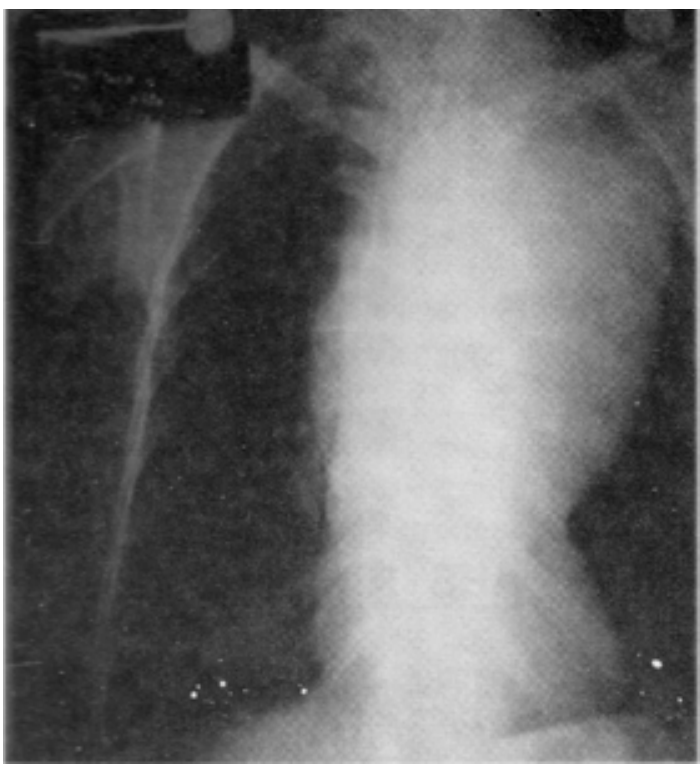

Figure 1: ChestX-ray PA showing the widening of the of the mediastinal shadow

ECG showed T wave inversion in the lead III, aVL and V2.

Echocardiography revealed aortic arch aneurysm of 11 $\mathrm{cm}$ in size. CT-Scan Thorax showed aneurysm of the arch of the aorta distal to the left common carotid artery, size $15 \mathrm{~cm}$ in oblique, $10 \mathrm{~cm}$ antero-posteriorly and $13.5 \mathrm{~cm}$ in vertical dimension. 


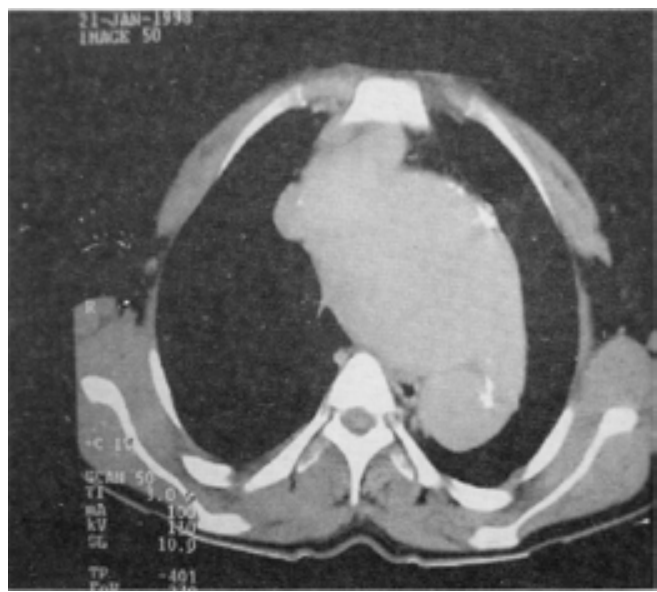

Figure 2: CT scan showing dilatation of the ascending aorta

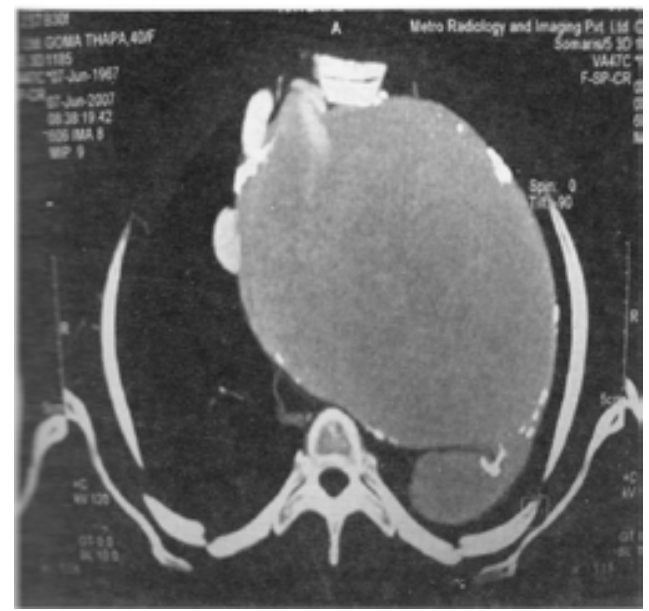

Figure 3: CT Scanning showing dilatation of the ascending aorta.

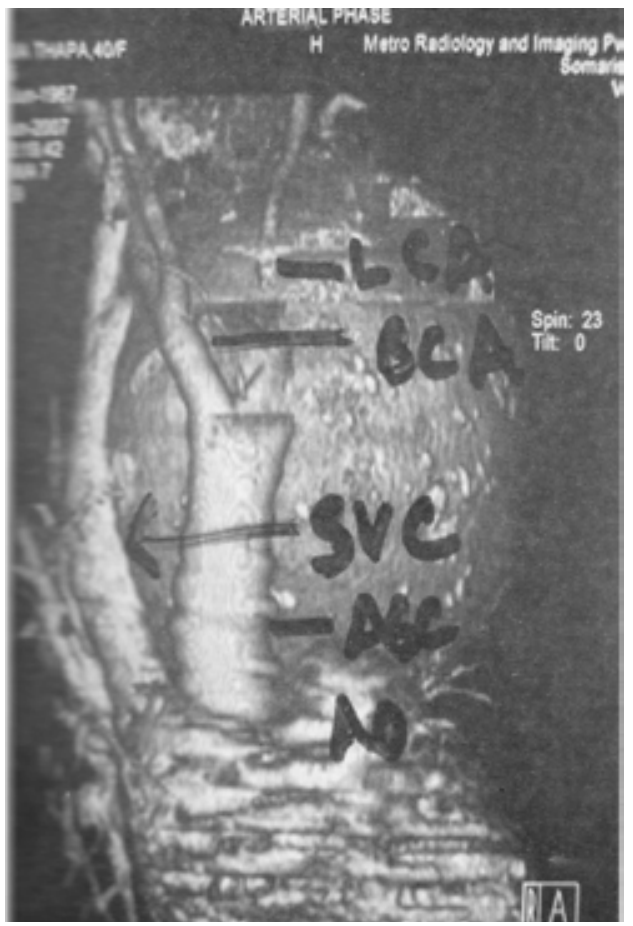

Figure 4: CT Angiogram showing the aneurysm

\section{Diagnosis:}

Aortic arch aneurysm ; colloid goitre.

Plan:

Aortic arch repair under deep hypothermic circulatory arrest (DHCA).

Anaesthesiologists, surgeons and perfusionists sat together and the respective problems and management plan about the case was discussed.

\section{Anaesthetic management: \\ Pre-anaesthetic assessment:}

History, general examinations, systemic examinations, all investigations were reviewed. Airway assessment was satisfactory but some consideration was given to difficult intubation and tracheomalacia. She was graded as ASA class III and malampatti class I airway assessment.

She was advised to continue atenolol $25 \mathrm{mg}$ as usual and diazepam $5 \mathrm{mg}$ at bedtime on the previous day and $5 \mathrm{mg}$ on the day o the surgery in the morning. Fasting after mid night.

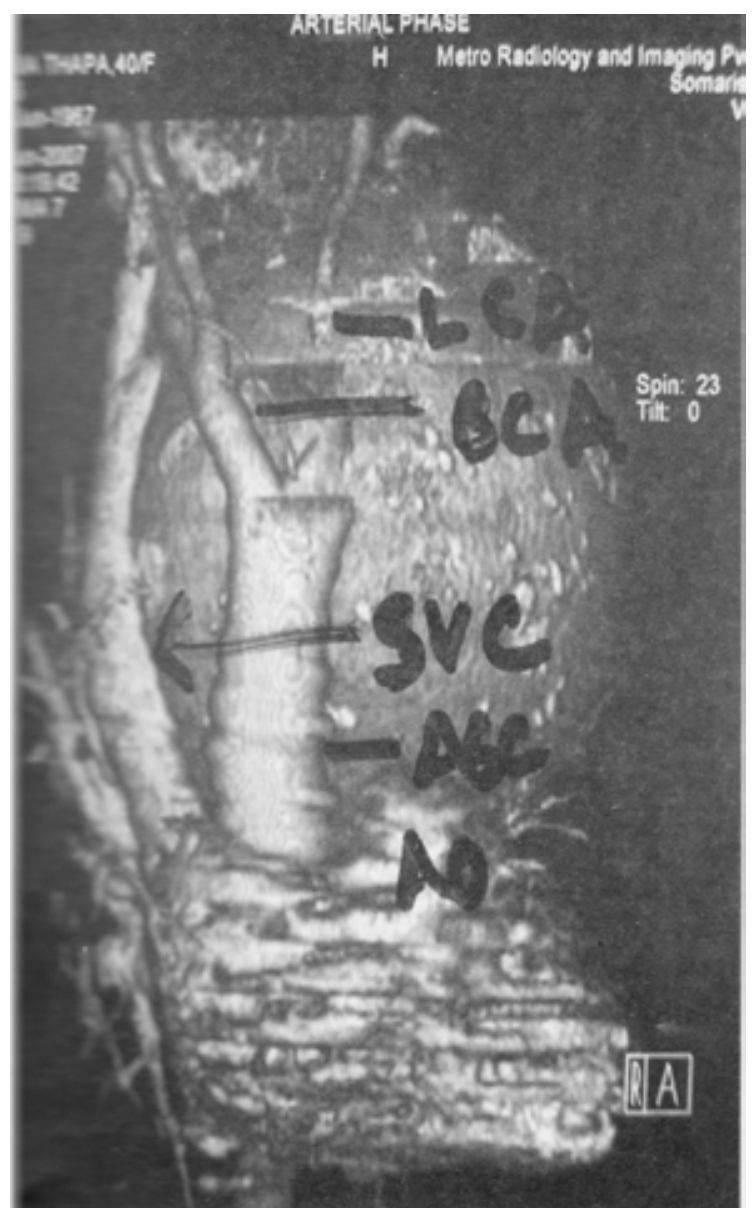

Figure 5: CT Angiogram showing aneurysm

\section{Intra-operative management:}

Patient was brought to the operation theatre. Two 16 G IV canulae were opened in both arms and $3 \mathrm{mg}$ of the midazolam was injected intravenously. One gm ceftriaxome and $80 \mathrm{mg}$ of the gentamycin was given intravenously. 


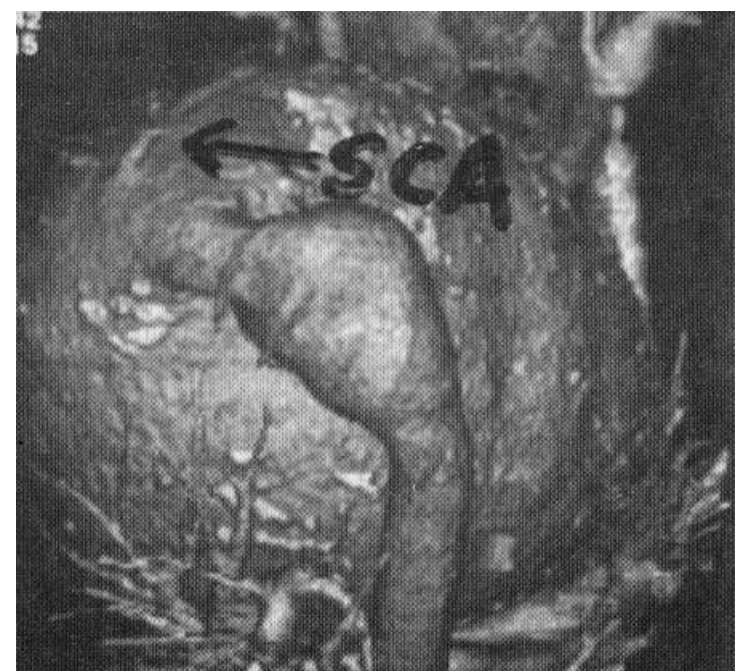

Figure 6: $C T$ angiogram showing the aneurysm

\section{Monitoring}

ECG and oxygen saturation probe was attached, two arterial lines were inserted into the right radial and left femoral arteries.

Central venous line (triple lumen) was inserted through the right internal jugular vein. Bladder catheterization was done and nasopharyngeal as well as rectal temperature probes were inserted. ABG and ACT were also monitored.

Anesthesia was induced with morphine $12 \mathrm{mg}$, propofol $50 \mathrm{mg}$, ketamine $40 \mathrm{mg}$ and vecuronium $8 \mathrm{mg}$ with stable haemodynamics.

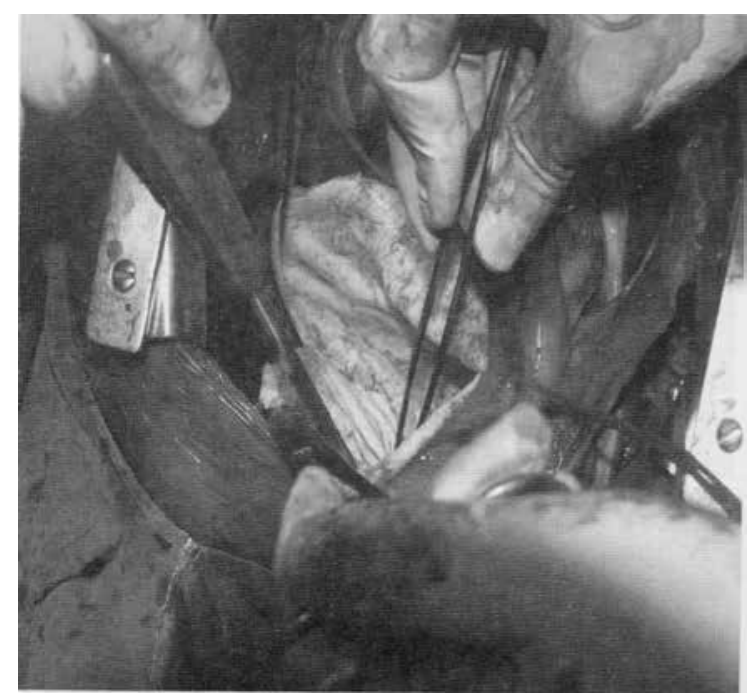

Figure 7: Aneurysm being opened

Surgery started with femoral artery an venous canulation. Patient was gradually cooled down on starting the cardiopulmonary bypass. The sternum was opened, aneurysmal sac was gradually mobilized. At 24 degree celsius the heart started to fibrillate. Cross clamp was applied and heart started to fibrillate. Cross clamp was applied and heart was arrested. Cooling weas further continued till 18 degree celsius. Some neuroprotecting drugs like sodium thiopentone $25 \mathrm{mg} / \mathrm{kg}$, methylprednisolone $25 \mathrm{mg} / \mathrm{kg}$ were injected before circulatory arrest. There was some perfusion in the lower part of the body through femoro-femoral bypass. Right axillary artery was canulated and distally clamped to facillitate the brain perfusion during circulatory arrest. Aortic arch was repaired with a graft.

Total bypass time: 247 mins (femoro-femoral bypass)

Total crossclamp time: 67 mins

Circulatory arrest was 34 mins

Patient was warmed up gradually and bypass was discontinued without any problem.

Hemostasis was secured

Five paints of fresh blood, 2 pints of Fresh Frozen Plasma and 10 pints of Ringer's Lactate solution were transfused.

\section{Post operative period:}

After completion of the surgery, patient was shifted to the SICU and ventilated electively. Patient was haemodynamically stable, neurologically there was no problem.

The patient was extubated after 15 hours of SICU stay. No neurological deficit was observed after extubation. She was shifted from the ICU on the 3 rd post operative day and discharged from hospital on the 6th post operative day.

\section{DISCUSSION}

Aortic arch repair is a complicated and complex type of the surgery and performed in the specialized centers where proper infrastructure, specialized manpower, and all the required facilities are available. Shahid Gangalal National Heart Centre is a specialized centre to take care of heart and major vascular diseases. Every year about 1000 cardiac and major vascular surgeries are performed in this centre.

Deep hypothemic circulatory arrest is the technique applied to protect brain and other organs when circulation is stopped completely or partially, for example during aortic arch surgery, complex cerebral aneurysm surgery, complex congenital heart surgery where there requires bloodless field to facilitate the repair. In these surgeries the issue of brain protection and prevention from adverse neurological events is very crucial.

There are options to operate only under DHCA (Deep Hypothermic Circulatory Arrest) or combined with DHCA and antegrade (also sometimes retrograde cerebral perfusion or very low flow perfusion and DHCA.

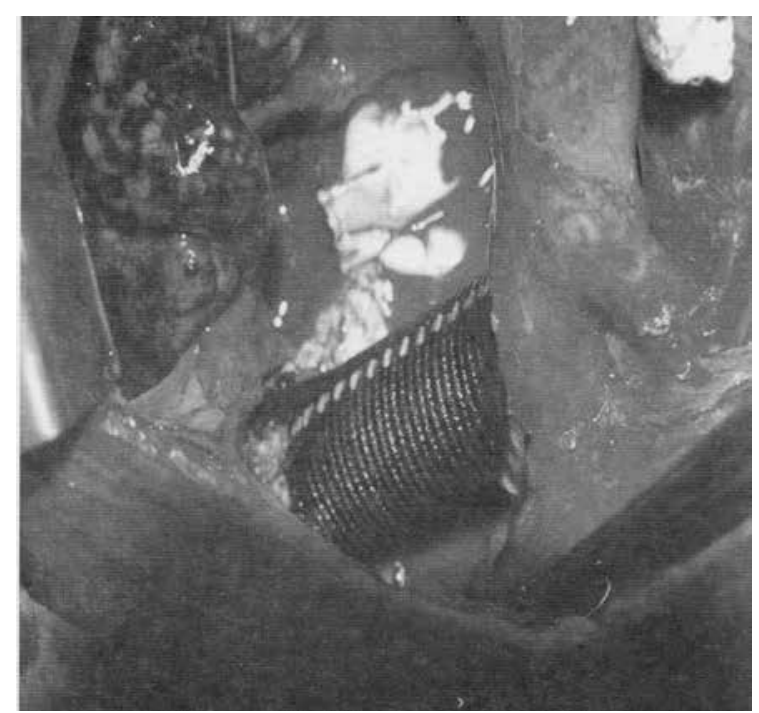

Figure 8: Intraoperative, showing graft 


\section{CONCLUSION}

This was the first aortic arch replacement in our hospital under Deep Hypothermic Circulatory arrest and was successfully and uneventfully completed. The combination of the antegrade perfusion and DHCA may be the crucial point for the neuroprotection and better neurological outcome.

\section{REFERENCE}

1. Yuzi Miyamoto, Kenzi Onishi, Masataka Mitluno, et al. Ann Thorac Cardiovasc Surg 2003; Vol 9, No 6, 389-393.

2. Cohn LH, Edmunds LH Jr, eds, Cardiac Surgery in the adults. New York: Mc Graw-Hill, 2003: 401-412

3. Swain JA, Mc Donald TJ jr, Grififth PK, et al: Low flow hypothermic cardiopulmonary bypass protects the brain.
J Thorac Cardiovasc Surg 1991;120:+76.

4. Svensson LG, Crawford ES, Hess KR, et al. Deep hypothermia with circulatory arrest. Determinants of stroke and early mortality in 656 patients. J Thorac Cardiovasc Surg 1993;106:19-28.

5. Koselli JS, Buket S, Dhukanovic B. Aortic arch operation : current treatment and results. Ann Thorac Surg 1995;59:19-27.

6. Okita Y, Minatoya K, Tagusari O, et al. Prospective comparative study of brain protection in total aortic arch replacement: deep hypothermic circulatory arrest with retrograde perfusion or selective antegrade cerebral perfusion. Ann Thorac Surg 2001;72:72-79. 